\title{
Effect of a probiotic on caecal microbial digestion in the pony
}

\author{
A de Vaux, $V$ Julliand \\ Laboratoire Associé de Recherches Zootechniques INRA-ENSSAA, 26, bd Dr-Petitjean, \\ 21000 Dijon, France
}

Three adult male ponies caecally fistulated were fed a maintenance ration of a complete meal $(89 \%$ dry matter, $16 \%$ cellulose, $15 \%$ crude protein) distributed at 8 am and $5 \mathrm{pm}$. The pellets were given alone during 1 month (D1), supplemented with $10 \mathrm{~g}$ (or $10^{10}$ spores) of mature spores of Bacillus CIP 5832 (BCIP5832)/day/animal for 5 weeks (D2) and unsupplemented again for 1 month (D3). For each period, 4 samples of caecal content were collected from each animal on 4 different days before distribution of the diet. Total and proteolytic bacteria were counted anaerobically into roll-tubes respectively on complete and specific solid media adapted from those of Leedle and Hespell (1981). The number of cellulolytic bacteria was determined anaerobically on a liquid medium adapted from Halliwell and Bryant's medium (1953) and expressed as the most probable number. Volatile fatty acids, crude protein and $\mathrm{NNH}_{3}$ were measured by gas chromatography, Kjeldahl's adapted technique and Conway's technique, respectively. Hay and straw degradabilities were measured using the in sacco method.

There were no significant differences for biochemical parameters between the 3 periods. There was no change in $\mathrm{pH}(7.0 \pm 0.2 ; 6.9 \pm 0.1 ; 6.7 \pm$ 0.2 in D1, D2, D3), VFA level $(57.1 \pm 13.4 ; 43.1 \pm$ 11.3; $57.3 \pm 9.3 \mathrm{mmol})$, total nitrogen level (5.0 \pm $0.6 ; 4.7 \pm 0.5 ; 4.5 \pm 0.7 \mathrm{~g} / 100 \mathrm{~g} \mathrm{DM})$ and $\mathrm{NNH}_{3}(74$ $\pm 13 ; 88 \pm 20 ; 83 \pm 13 \mathrm{mg} / 1)$. In sacco degradations showed no significant differences. The percentages of disappearance of DM $(48.9 \pm 6.4 ; 43.4 \pm$ $5.1 ; 45.5 \pm 3.6)$ and cellulose $(35.9 \pm 10.2 ; 26.1 \pm$ $9.7 ; 29.3 \pm 7.4)$ from hay, DM $(24.4 \pm 4.9 ; 23.4 \pm$ $4.0 ; 23.1 \pm 2.9)$ and cellulose $(19.1 \pm 10.3 ; 17.7 \pm$ $8.7 ; 18.3 \pm 8.6$ ) from straw were similar. BCIP5832 increased the number of total and proteolytic caecal bacteria in 2 ponies but the means of the 3 animals were not significantly different. The probiotic had no significant effects on the cellulolytic flora of the 3 animals (fig 1).

In conclusion, BCIP5832 had no effects on cellulolytic activity but it could allow the host to increase nitrogenous nutrient availability.

Halliwell G, Bryant MP (1953) J Gen Microbiol $32,441.448$

Leedle JAZ, Hespell RB (1981) App/ Environ Microbio/ 39, 709-719

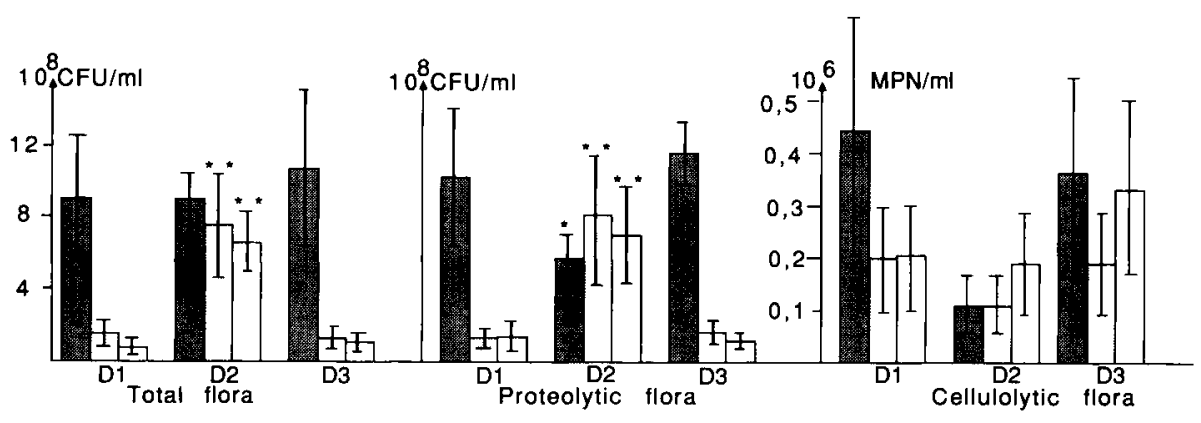

Fig 1. Counts of caecal bacterial populations. Pony 1; $\square$ Pony $2 ; \square$ Pony 3. ${ }^{\star} p<0.01$; ** $p<0.001$. 